\title{
Results of scanning for diabetes, obesity and blood pressure: a sample from manisa in western turkey
}

\author{
Abstract \\ Objectives: We aimed to create awareness of diabetes, hypertension and obesity by \\ carrying out scanning for these illnesses. \\ Design: The study designed descriptive. \\ Setting: One hospital in the Turkey. \\ Method: The study was planned descriptive in order to create awareness of diabetes, obesity \\ and hypertension by scanning these diseases with 210 participating individuals in Manisa \\ State Hospital Garden on 24 December 2014. For scanning in the research, we used five \\ glucometers for fingertip capillary blood glucose measurement, three sphygmomanometers, \\ and two scales for size-weight measure. A data collection form developed by the researchers \\ was used. Data were analyzed using the SPSS 15.0 software package.
}

Results: It was found in the study that mean blood glucose levels, systolic blood pressure, diastolic blood pressure and BMI increased with increasing age of the individuals $(p<0.005)$. It was determined that there was no significant relationship between gender and blood glucose, systolic blood pressure, diastolic blood pressure and BMI ( $p>0.05$ ).

Conclusion: The results of the screening showed a total of 23 people with blood sugar levels of $200 \mathrm{mg} / \mathrm{dL}$ or diabetic. Of these 23 people, 16 were female and seven were male.

Keywords: diabetes, obesity, hypertension, screening

\author{
Volume 5 Issue I - 2018 \\ Nurgul Güngör Tavșanli,' Seçil Köken,' Selin \\ Ülger Akıncıoğlu,' Havva Artuvan,' Zeynep \\ Nerse ${ }^{2}$ \\ 'Manisa Celal Bayar University Health Sciences Faculty, Turkey \\ ${ }^{2}$ Manisa Government Hospital, MANISA, Turkey
}

Correspondence: Nurgül Güngör Tavșanli, Manisa Celal Baya Üniversitesi, Sağlık Bilimleri Fakültesi, Uncubozköy Yerleșkesi, Manisa, Turkey,Tel +90236239 I3।8, Fax +90 2362320058 , Email nurgul.gungor@hotmail.com

Received: August 24, 2017 | February 19, 2018

\section{Background}

In WHO rankings, diabetes has been recognized as being in the group of rapidly increasing epidemiological diseases. ${ }^{1}$ It was found that there were 400million adult diabetics in the world in 2015, and this number is predicted to rise to over 640 million by 2040 . Seventyfive percent of diabetics in the world live in medium and low income countries, and five million people in the world die of diabetes each year. The cost of medical care for diabetic individuals is more than 670billion dollars annually according to the IDF. ${ }^{2}$ According to the results of a 2010 study by Diabetes Epidemiology in Turkey (TURDEP II), the prevalence of diabetes is $13.7 \%$, the prevalence of obesity is $32 \%$, and the prevalence of hypertension is $30 \%{ }^{3}$

\section{Introduction}

Diabetes is a chronic metabolic disease in which the organism cannot make adequate use of carbohydrates, fats and proteins because of insulin deficiency or defects in sensitivity to insulin, resulting in the need for constant medical care. ${ }^{4}$ All adults should be assessed for type 2 diabetes risk factors, according to their demographic and clinical characteristics. Diabetes scanning should be carried out on obese or overweight individuals (BMI $\geq 25 \mathrm{~kg} / \mathrm{m}^{2}$ ) and especially on those with central obesity (waist measurement of $\geq 88 \mathrm{~cm}$ in women and $\geq 102 \mathrm{~cm}$ in men) three times a year from the age of 40 , and for preference Fasting Plasma Glucose (FPG) and diabetes scanning. In addition, those with a BMI of $\geq 25 \mathrm{~kg} / \mathrm{m}^{2}$ should be investigated more frequently and from a younger age if they fall into one of the risk groups below:,

i. Those with first-degree relatives with diabetes,

ii. Those from ethnic groups with a high prevalence of diabetes, iii. Women who have given birth to large babies or who have been diagnosed with Gestational Diabetes Mellitus (GDM),

iv. Hypertensive individuals (blood pressure $\geq 140 / 90 \mathrm{mmHg}$ ),

v. Dyslipidemics (HDL-cholesterol $\leq 35 \mathrm{mg} / \mathrm{dl}$ or triglyceride $250 \mathrm{mg} / \mathrm{dl})$,

vi. Those with previous abnormal fasting glucose or abnormal glucose tolerance,

vii. Women with polycystic ovary syndrome,

viii. Those with clinical disease or findings relating to insulin resistance (acanthosis nigricans),

ix. Those with coronary, peripheral or cerebral vascular disease,

$\mathrm{x}$. Those born with low birth weight,

xi. Those with a sedentary lifestyle or with low physical activity,

xii. Those with a diet rich in saturated fats and low in fiber,

xiii. Schizophrenia patients and those using antipsychotic drugs,

xiv. Patients who have undergone solid organ (especially renal) transplantation. ${ }^{4,5}$

The simplest method of diabetes scanning is random plasma glucose measurement. In this method, blood sugar is measured randomly at any time of day, and values of $200 \mathrm{mg} / \mathrm{dl}$ or above lead to a diagnosis of diabetes mellitus. If an individual's blood sugar level is $200 \mathrm{mg} / \mathrm{dl}$ or above and if there are any of the basic symptoms and signs of diabetes such as polyuria, polydipsia, polyphagia, unexplained weight loss, blurred vision, unexpectedly late healing of wounds 
or infections or an increase in sleepiness, the individual should be sent to endocrinology and definite diagnosis and treatment should be set in motion. ${ }^{5,6}$ Hypertension is a disorder of Blood Pressure (BP) regulation, and is a rise in blood pressure above the normally accepted limits. BP should be categorized as normal, elevated, or stages 1 or 2 hypertension to prevent and treat high BP. Normal BP is defined as $<120 /<80 \mathrm{mmHg}$; elevated BP $120-129 /<80 \mathrm{mmHg}$; hypertension stage 1 is $130-139$ or $80-89 \mathrm{mmHg}$, and hypertension stage 2 is $\geq 140$ or $\geq 90 \mathrm{mmHg}$. A systolic blood pressure of $90 \mathrm{mmHg}$ or above is defined as hypertension 10. Previous guidelines identified high blood pressure as $\geq 140 / 90 \mathrm{mmHg}$. In the literature now, systolic blood pressure of $130 \mathrm{mmHg}$ or more is known as systolic hypertension, diastolic blood pressure of $80 \mathrm{mmHg}$ or above as diastolic hypertension, and both together as mixed (systo-diastolic) hypertension. ${ }^{7-10}$ Obesity is defined by the WHO as "an abnormal or excessive accumulation of fat such as to disrupt health". ${ }^{1}$ Also, obesity is defined as a multifactorial disease arising from genetic, metabolic, social, behavioral and cultural factors. ${ }^{11}$ Today, the most commonly used anthropometric method of assessing obesity is body mass index (BMI). This is calculated as weight divided by height squared $\left(\mathrm{kg} / \mathrm{m}^{2}\right) .{ }^{12}$ According to the WHO, a BMI of over $25 \mathrm{~kg} / \mathrm{m}^{2}$ is classed as overweight, and $30 \mathrm{~kg} / \mathrm{m}^{2}$ or more as obese. ${ }^{1}$

\section{Objectives}

We aimed to create awareness of diabetes, hypertension and obesity by carrying out scanning for these illnesses.

\section{Methods}

\section{Participants}

This descriptive type research was conducted with a population of the individuals in the garden of Manisa State Hospital, which is attached to the Secretariat of the Public Hospitals Association of Manisa Province. No sampling method was applied in the research, and the research was performed on 210 individuals who volunteered to participate in the diabetes scanning, chosen by a simple random sampling method.

\section{Ethical considerations}

Before starting the research, permission was obtained from the Ethics Committee of Celal Bayar University Medical Faculty, dated 17.12.2014 and numbered 20478486-410. Also, written permission was obtained from the Secretariat of the Manisa Province Public Hospitals Association of the Ministry of Health and from the office of the Head Physician of Manisa State Hospital. The individuals participating in the study were given information on the purpose and the content of the study, and their written and oral permission was obtained.

\section{Instruments}

Five strip glucometer instruments measuring glucose from fingertip capillaries, three sphygmomanometer blood pressure instruments and two scales measuring height and weight were used to conduct the scan. A form developed by the researchers recording the participant's name, address, telephone number, age, gender, height, weight, and blood sugar and blood pressure measurement results was used to collect data.

\section{Statistical analysis}

The package SPSS 15.0 was used in the statistical analysis of the findings obtained in the research. In evaluation of the data, Kruskal Wallis (It is used to investigate whether there is a difference between the mean of three or more groups in non-normal distribution groups. For example, it is like examining the difference between 20-24 age, 25-29 age and 30-34 age groups) and Independent $t$ test analyses (Two independent sample T-tests are used to investigate whether there is a difference between the two sample groups in terms of averages. characteristics. For example, two independent sample $\mathrm{t}$ tests are used to look at the difference between male and female) were used with descriptive analyses such as frequency, percentage, mean, and standard deviation.

\section{Results}

Table 1 shows the age and gender of the individuals scanned. It can be seen from Table 1 that $60 \%$ of the individuals scanned $(n=126)$ were female, and that their mean age was $50.84 \pm 14.47$ ( $\min =10$ $\max =92$ ) years. Considering the individuals scanned by age groups, it is seen that $26.7 \%(n=56)$ fell into the $41-50$ age group, $24.3 \%(n=$ $51)$ into the $51-60$ age group, $16.7 \%(n=35)$ into the $61-70$ age group, and $16.2 \%(\mathrm{n}=34)$ into the $31-40$ age group (Table 1). Table 2 shows the values of the individuals' blood sugar, blood pressure and BMI. The individuals' mean blood sugar value was $130.12 \pm 68.72 \mathrm{mg} /$ dl $(\min =57 \max =469)$, their mean systolic blood pressure was $129.36 \pm 24.69 \mathrm{mmHg}(\min =90 \mathrm{max}=220)$, and their mean diastolic blood pressure was $76.99 \pm 14.77 \mathrm{mmHg}(\mathrm{min}=50 \mathrm{max}=140)$. Their mean BMI was $28.32 \pm 5.93 \mathrm{~kg} / \mathrm{m}^{2} \quad(\min =15.94 \mathrm{max}=51.56)$ (Table 2). In Table 3 an investigation was made of the relationship between the metabolic values of the individuals scanned and their age groups and gender. A statistically significant correlation was found between the individuals' age groups and their mean blood sugar values $\left(\mathrm{X}^{2}=\right.$ $20.350 \mathrm{p}=0.005^{*}$ Kruskal Wallis). Mean blood sugar values in the 5160 age group were found to be highest with a mean of $145.96 \pm 26.24$ (Table 3). The individuals' mean blood sugar levels showed a rise with age up to the age of 60 , but in the 61 and above age groups it fell somewhat (Table 3). A statistically significant correlation was found between the individuals' age groups and their mean systolic $\left(\mathrm{X}^{2}=23.920 \mathrm{p}=0.001 *\right.$ Kruskal Wallis $)$ and diastolic $\left(\mathrm{X}^{2}=16.906\right.$ $\mathrm{P}=0.018^{*}$ Kruskal Wallis) blood pressure values. The highest levels were found in the 71-80 and 81-90 and above age groups with a mean systolic blood pressure of $145 \mathrm{mmHg}$, and in the $61-70,71-80$ and $81-90$ and above age groups with a mean diastolic blood pressure of $80-87.50 \mathrm{mmHg}$. It was seen that the mean systolic and diastolic blood pressures of the individuals increased with age (Table 3 ).

The correlation between the individuals' age groups and their mean BMI was found to be statistically significant $\left(\mathrm{X}^{2}=27.665 \mathrm{p}=0.000\right.$ * Kruskal Wallis). Mean BMI values in the 41-50, 51-60 and 61-70 age groups were the highest at 28.96 to 29.96 , which is overweight according to the WHO. These three groups were close to the obesity threshold of $30 \mathrm{~kg} / \mathrm{m}^{2}$. Mean BMI values showed an increase up to the age of 70, and fell somewhat in the 71 and above age group (Table 3). No statistically significant correlation was found between the individuals' gender and their blood sugar, systolic blood pressure, diastolic blood pressure or BMI ( $p>0.05$ Independent $t$ test) (Table 3 ). In Table 4, the blood sugar values of individuals in the scanned groups were ranked according to the blood sugar values of the Turkish Diabetes and Obesity Foundation. Blood sugar values were normal (below $140 \mathrm{mg} / \mathrm{dl}$ ) in 90 females and 67 males, a total of 157 people. Twenty five people-17 females and eight males-had blood sugar levels of $141-199 \mathrm{mg} / \mathrm{dl}$ (Impaired Glucose Tolerance or possibly diabetic), and 23 people ( 16 female and seven male) had blood sugar values of over $200 \mathrm{mg} / \mathrm{dl}$ (diabetic) (Table 4). 
Table I Individuals' Identifying Characteristics

\begin{tabular}{llll}
\hline Characteristics & Avg士SD & Min & Max \\
\hline Age & $50.84 \pm 14.47$ & 10 & 92 \\
Gender & $\mathbf{n}$ & $\%$ & \\
Female & 126 & 60 & \\
Male & 84 & 40 & \\
Age groups & $\mathbf{n}$ & $\%$ & \\
10-20years & 3 & 1.4 & \\
21-30years & 14 & 6.7 & \\
31-40years & 34 & 16.2 & \\
41-50years & $\mathbf{5 6}$ & $\mathbf{2 6 . 7}$ & \\
51-60years & $\mathbf{5 1}$ & $\mathbf{2 4 . 3}$ & \\
6I-70years & 35 & 16.7 & \\
71-80years & 13 & 6.2 & 1.9 \\
81-90years and over & 4 & 100 & \\
Total & 210 & &
\end{tabular}

Table 2 Individuals' Metabolic Values

\begin{tabular}{llll}
\hline Metabolic values & Avg士SD & Min & Max \\
\hline Blood sugar $(\mathrm{mg} / \mathrm{dl})$ & $130.12 \pm 68.72$ & 57 & 469 \\
Systolic blood pressure $(\mathrm{mmHg})$ & $129.36 \pm 24.69$ & 90 & 220 \\
Diastolic blood pressure $(\mathrm{mmHg})$ & $76.99 \pm 14.77$ & 50 & 140 \\
BMI $\left(\mathrm{kg} / \mathrm{m}^{2}\right)$ & $28.32 \pm 5.93$ & 15.94 & 51.56 \\
\hline
\end{tabular}

\section{Discussion}

It was found that as the age groups of the individuals in the study increased, their mean blood sugar level, systolic blood pressure, diastolic blood pressure and BMI values also increased (Table 3). According to 2010 data from the Turkish Diabetes, Hypertension, Obesity and Endocrinological Diseases Prevalence Study (TURDEP II), the prevalence of diabetes in the adult Turkish population has reached $13.7 \%,{ }^{3}$ and according to IDF 2015 data, more than 415 million people in the world are diabetic and $46 \%$ of diabetics in the world have not been diagnosed. ${ }^{2}$ A statistically significant correlation was found in the scan between age groups and blood sugar levels $\left(\mathrm{X}^{2}=20.350 \mathrm{p}=0.005^{*}\right.$ Kruskal Wallis $)$. Blood sugar levels were highest in the 51-60 age group, with a mean value of $145.96 \pm 26.24$ (Table 3). According to 1998 data from the Turkish Diabetes, Hypertension, Obesity and Endocrinological Diseases Prevalence Study (TURDEP I), more than $10 \%$ of the frequency of diabetes begins in the 45-49year age group. ${ }^{13} \mathrm{~A}$ welcome finding of the present study was that blood sugar levels were high at a more advanced age than in the TURDEP-I study. In TURDEP II the frequency of diabetes was found to be slightly higher in females than in males, but there was no significant difference between males and females. ${ }^{3}$ In the present study as in the TURDEP II study, the mean blood sugar levels of females were found to be slightly higher than those of males (Table 4). A total of 23 individuals-16 females and 7 males-had blood sugar levels of over $200 \mathrm{mg} / \mathrm{dl}$ (diabetic) when scanned in the study (Table 4).

However, no statistically significant correlation was found between gender and mean blood sugar levels (Table 3). As the 2015 IDF diabetes atlas states, scanning for diabetes is important for preventing complications and for early diagnosis and treatment. In the world, one adult in two has undiagnosed diabetes. ${ }^{2}$ This shows that diabetes is a significant public health problem. In the scan, a statistically significant correlation was found between the individuals' age groups and their mean BMI values $\left(X^{2}=27.665 \mathrm{p}=0.000 *\right.$ Kruskal Wallis $)$. Mean BMI values were highest (28.96-29.96) in the 41-50, 51-60 and 61-70 age groups. These three groups approached the obesity threshold of $30 \mathrm{~kg} /$ $\mathrm{m}^{2}$, and mean BMI values increased with age until the age of 70 . Today, the most frequently used anthropometric method of assessing obesity is BMI. ${ }^{12}$ According to the WHO, a BMI of over $25 \mathrm{~kg} / \mathrm{m}^{2}$ is classified as overweight, and those with a BMI of over $30 \mathrm{~kg} / \mathrm{m}^{2}$ are classified as obese. ${ }^{1}$ According to 2010 data in the TURDEP II study, the frequency of obesity in Turkey was found to be $32 \%$, and it has increased by $44 \%$ in 12 years. ${ }^{3}$ In the TEKHARF study, the prevalence in a 30year-old cohort in 2001-2002 was $23.5 \%$ in males and $44.2 \%$ in females. ${ }^{14}$ In a study by Oğuz et al ${ }^{15}$ with 4264 participants in four different regions of Turkey, the prevalence of obesity was found to be $30.4 \%$, and the prevalence of overweight was $36 \% .{ }^{15}$

As WHO data and these studies show, BMI increases with advancing age and is increasing over time in the country in general. It was found that the correlation between the individuals' age groups and their mean systolic $\left(X^{2}=23.920 \mathrm{p}=0.001 *\right.$ Kruskal Wallis $)$ and diastolic $\left(\mathrm{X}^{2}=16.906\right.$ $\mathrm{P}=0.018^{*}$ Kruskal Wallis) blood pressure values was statistically significant. It was found that as their age increased their mean systolic and diastolic blood pressure also increased (Table 3). The hypertension rate in the TURDEP II study as in the TURDEP I study was found to be approximately $30 \%$ and the male-female and urban-rural differences were lost. ${ }^{3}$ According to the WHO 2012 statistics report, one in three adults has high blood pressure and blood pressure increases with age. ${ }^{7}$ According to data for 2010 from the Centers for Disease Control and Prevention (CDC) in America, there are 59259 cases of hypertension aged 18 or over, of whom 21425 are persons aged 65 or over. ${ }^{7,16}$ As stated in the results of these studies, it is observed that blood pressure increases in direct relationship with increasing age. The results of our scanning are similar to those of other studies.

Table 3 Correlation between Metabolic Values, Age Groups and Gender

\begin{tabular}{|c|c|c|c|c|c|}
\hline $\begin{array}{l}\text { Identifying } \\
\text { characteristic }\end{array}$ & $\mathbf{N}$ & $\begin{array}{l}\text { Blood sugar } \\
\text { (Mg/DI) }\end{array}$ & $\begin{array}{l}\text { Systolic blood } \\
\text { pressure(Mmhg) }\end{array}$ & $\begin{array}{l}\text { Diastolic blood } \\
\text { pressure(Mmhg) }\end{array}$ & $\begin{array}{l}\text { BMI } \\
\left(\mathrm{Kg} / \mathrm{m}^{2}\right)\end{array}$ \\
\hline Age groups(KW) & & $\begin{array}{l}X^{2}=20.350 \\
p=0.005 *\end{array}$ & $X^{2}=23.920 p=0.00 I^{*}$ & $X^{2}=16.906 P=0.018^{*}$ & $\begin{array}{l}X^{2}=27.665 \\
p=0.000 *\end{array}$ \\
\hline 10-20years & 3 & $129.33 \pm 48.23$ & $1 \mid 3.33 \pm 11.54$ & $50.00 \pm 17.32$ & $19.34 \pm 2.72$ \\
\hline $21-30$ years & 14 & $90.35 \pm 12.85$ & $111.42 \pm 15.11$ & $70.71 \pm 12.06$ & $23.28 \pm 5.10$ \\
\hline 31-40years & 34 & $130.09 \pm 89.83$ & $|20.58 \pm| 7.9 \mid$ & $75.58 \pm 12.06$ & $28.21 \pm 7.20$ \\
\hline
\end{tabular}




\begin{tabular}{|c|c|c|c|c|c|}
\hline $\begin{array}{l}\text { Identifying } \\
\text { characteristic }\end{array}$ & $\mathbf{N}$ & $\begin{array}{l}\text { Blood sugar } \\
\text { (Mg/DI) }\end{array}$ & $\begin{array}{l}\text { Systolic blood } \\
\text { pressure(Mmhg) }\end{array}$ & $\begin{array}{l}\text { Diastolic blood } \\
\text { pressure(Mmhg) }\end{array}$ & $\begin{array}{l}\mathrm{BMI} \\
\left(\mathrm{Kg} / \mathrm{m}^{2}\right)\end{array}$ \\
\hline Age groups(KW) & & $\begin{array}{l}X^{2}=20.350 \\
p=0.005^{*}\end{array}$ & $\mathrm{X}^{2}=23.920 \mathrm{p}=0.00 \mathrm{I} *$ & $X^{2}=16.906 P=0.018 *$ & $\begin{array}{l}X^{2}=27.665 \\
p=0.000 *\end{array}$ \\
\hline $4 I-50$ years & 56 & $|28.8| \pm 64.44$ & $129.45 \pm 24.60$ & $78.00 \pm 14.58$ & $28.96 \pm 5.50$ \\
\hline 5I-60years & 51 & | $45.96 \pm 26.24$ & $130.00 \pm 24.32$ & $76.80 \pm 13.79$ & $29.96 \pm 5.79$ \\
\hline 6I-70years & 35 & $127.80 \pm 64.36$ & $138.52 \pm 27.09$ & $80.88 \pm I 5.83$ & $29.18 \pm 4.38$ \\
\hline 7I-80years & 13 & $|20.9| \pm 3 \mid .55$ & $\mid 45.00 \pm 28.44$ & $80.00 \pm 14.14$ & $25.99 \pm 5.02$ \\
\hline $\begin{array}{l}81-90 y e a r s \text { and } \\
\text { over }\end{array}$ & 4 & $133.75 \pm 35.42$ & $145.00 \pm 23.80$ & $87.50 \pm 9.57$ & $23.69 \pm 4.52$ \\
\hline Gender (t test) & & $\begin{array}{l}t=-0.885 \\
p=0.388\end{array}$ & $t=-0.818 p=0.414$ & $\mathrm{t}=-1.250 \mathrm{P}=0.213$ & $\begin{array}{l}t=-0.568 \\
p=0.570\end{array}$ \\
\hline Female & 126 & $133.52 \pm 70.16$ & $|28.2| \pm 26.02$ & $75.93 \pm 15.77$ & $28.15 \pm 6.33$ \\
\hline Male & 84 & $|25.03 \pm 66.6|$ & $131.08 \pm 22.63$ & $78.55 \pm 13.07$ & $28.61 \pm 5.30$ \\
\hline
\end{tabular}

Kruskal Wallis $(\mathrm{KW})$ Independent $\mathrm{t}$ test $(\mathrm{t}$ test $) * \mathrm{p}<0.005$ is significant

Table 4 Rates of Diabetes in Individuals Scanned

\begin{tabular}{|c|c|c|c|c|c|}
\hline Rates of diabetes & Female & Male & Total & Pearson chi-square & $\mathbf{P}$ \\
\hline Below $140 \mathrm{mg} / \mathrm{dl}$ - Normal & 90 & 67 & 157 & & \\
\hline$|4|-199 \mathrm{mg} / \mathrm{dl}$ - Impaired glucose tolerance (possibly diabetic) & 17 & 8 & 25 & & \\
\hline Above $200 \mathrm{~m} / \mathrm{dl}$ - diabetic & 16 & 7 & 23 & & \\
\hline Total & 123 & 82 & 205 & & \\
\hline
\end{tabular}

\section{Limitations}

This study has several limitations. First, the sample was recruited from only one city in Turkey. It was not conducted with participants living in different areas. Second, the sample size could have been larger if more opportunities to conduct the survey at more convenient research sites had been chosen and organized. Thus, this discussion cannot be generalized to frail populations in the community.

\section{Conclusion}

It was found in the study that as the individuals' age groups increased, their mean blood sugar levels, systolic and diastolic blood pressure and BMI values also increased. No significant correlation was found between the individuals' gender and their blood sugar, systolic and diastolic blood pressure or BMI. Scan results indicated that, as with the findings of prevalence studies conducted in the country as a whole such as TURDEP I, TURDEP II and TEKHARF and the IDF 2015 atlas, diabetes, obesity and hypertension are important public health problems in this country as in the world.

\section{Acknowledgement}

We wish to thank the company Roche Diagnostic, the graduate students of the Midwifery Department of the Health Sciences Faculty of Celal Bayar University, Manisa, and all those who participated in our scanning study.

\section{Conflict of interest}

Author declares that there is no conflict of interest.

\section{References}

1. World Health Organisation. WHO. World Health Statistics 2015: Part II Highlighted topics, Switzerland; 2015.

2. International Diabetes Federation. World Diabetes Day resources. 2015.

3. Satman I, Imamoglu S, Yilmaz C, et al. A patient-based study on the adherence of physicians to guidelines for the management of type 2 diabetes in Turkey. Diabetes Res Clin Pract. 2012;98(1):75-82.

4. Türk Endokrinoloji ve Metabolizma Derneği. Diabetes Mellitus Ve Komplikasyonlarinin Tani, Tedavi Ve İzlem Kilavuzu. 2017.

5. American Diabetes Association. Standards of Medical Care in Diabetes-2017 Abridged for Primary Care Providers. Clin Diabetes. 2017;35(1):5-26.

6. Aksoy DY, Gürlek A, Cetinkaya Y, et al. Change in the amputation profile in diabetic foot in a tertiary reference center: efficacy of team working. Exp Clin Endocrinol Diabetes. 2004;112(9):526-530.

7. Arinsoy T, Deger SM, Ates K, et al. Prevalence of Chronic Kidney Disease in Turkish Adults With Obesity and Metabolic Syndrome: A Post Hoc Analysis from Chronic Renal Disease in Turkey Study. J Ren Nutr. 2016;26(6):373-379.

8. Altun B, Arici M, Nergizoğlu G, et al. Prevelance, awareness, treatment and control of hypertension in Turkey (the PatenT study) in 2003. $J$ Hypertens. 2005;23(10):1817-1823.

9. Hypertension Clinical Guidelines. 2017.

10. ACC News Story. New ACC/AHA High Blood Pressure Guidelines Lower Definition of Hypertension. ACC. 2017.

11. Kolotkin RL, Meter K,Williams GR. Quality of Life and Obesity. Obes Rev. 2001;2(4):219-229. 
12. Tugay Aytekin N, Pala K, Irgil E, et al. Distribution of blood pressures in Gemlik District, north-west Turkey. Health Soc Care Community. 2002;10(5):394-401.

13. Satman I, Yilmaz T, Sengül A, et al. Population-based study of diabetes and risk characteristics in Turkey. results of the turkish diabetes epidemiology study (TURDEP). Diabetes Care. 2002;25(9):1551-1556.

14. Onat A, Çakır H, Karadeniz Y, et al. Turkish Adult Risk Factor survey 2013: rapid rise in the prevalence of diabetes. Turk Kardiyol Dern Ars. 2014;42(6):511-516.
15. Oğuz A, Temizhan A, Abaci A, et al. Obesity and abdominal obesity; an alarming challenge for cardio-metabolic risk in Turkish adults. Anadolu Kardiyol Derg. 2008;8(6):401-406.

16. National Center for Health Statistics. Health, United States, 2010: With Special Feature on Death and Dying. USA; 2010. 